\title{
PARENT SATISFACTION WITH TREATMENT AND CARE SERVICES WITHTIN THE FRAMEWORK OF PEDIATRIC PALLIATIVE CARE IN LATVIA
}

\author{
Inta Kalniņa \\ Liāna Deklava \\ Rīga Stradiņš University, Latvia
}

\begin{abstract}
The number of children prenatally or after birth diagnosed with a disease with no prevent radical treatment options in Latvia and worldwide constantly increases. Pediatric palliative care in Latvia is organized in the form of a home hospice care model. It is instrumental to establish the level of patients' satisfaction with the provided care and treatment services. The objective of the study is to evaluate patient satisfaction with care and treatment services under the offered pediatric palliative care model. The study sample comprises 153 parents with children receiving palliative care services. The study is based on the quantitative research method: patient satisfaction survey. The parental satisfaction was measured in six subcategories: networking and collaboration, follow-up care, funding, access, clinical capacity building and outreach. According to the outcomes of the study, the level of satisfaction with the provided treatment and care services under the hospice palliative care model is average. The lowest score was given to collaboration and access categories, whereas the highest score was awarded for the continuity (follow-up) of care and funding.
\end{abstract}

Keywords: incurable disease, pediatric palliative care model, satisfaction.

\section{Introduction}

Adult palliative care is known for long, however, what concerns the pediatric care - it is a new subspeciality (Pelant et al., 2012; Moore \& Sheetz, 2014). Pediatric palliative care comprises active, fully comprehensive care of children with progressive chronic diseases in case all radical treatment options have been exhausted. The family with an incurably sick child is at the forefront of pediatric palliative care. The objective of palliative care is to ensure possibly better quality of life for patients and their families. Such type of care combines alleviation of pain and other symptoms with psychological, social, and spiritual support, allowing the patient to feel maximally comfortable and making it possible for the child to use its functional abilities to the extent maximally possible, ensuring such level of care that would make him feely as good as possible and would listen to his wishes. 
Pediatric palliative care is available in Latvian since 1998 and it is implemented in the form of home hospice palliative care model. The pediatric palliative care is not equally accessible to all palliative care patients as the service is provided to patients living in Riga and Kurzeme regions. The number of patients from other geographical regions of Latvia receiving palliative care service is limited. In case of aggravation, these children may receive stationary medical assistance at hospitals with special pediatric treatment departments, nevertheless these institutions provide no palliative care. Children with palliative care status may receive medical services at day centres that provide palliative care and long stay social care institutions.

Due to the increasing number of children requiring palliative care, the topic is gaining topicality. In 2012 pediatric palliative care at home under the supervision of palliative care service was received by 143 patients, in 2013 by 159 patients and in 2014 by 164 patients (BPAB data). Currently palliative care at home is provided by two organizations and the service is also ensured by longstay and short-stay social rehabilitation facilities. In the absence of a coordinated system for the care of incurably sick children and their family members, and considering that pediatric palliative care has not been marked out as a separate area of healthcare, the purposeof this article is to evaluate patients' satisfaction with the access to medical treatment and care services in Latvia within the framework of the existing palliative care pattern. The survey is based upon the quantitative research method, involving 153 parents with a child who receives palliative care services. We use two research tools: sociodemograpfic survey and patient satisfaction survey. Patient satisfaction survey consists of 39 questions. All questions are divided in 6 subcategories: networking and collaboration, follow-up care, funding, access, clinical capacity building and outreach. Each question evaluted in Likert`s scale. For determination of internal coherence, we use coefficient of Cronbach`s alfa.The Cronbach`s alfa in all subscales is from 0,53 to 0,72 , wich indicates moderate and high reliability. For data processing we use frequency calcualtion - average and standart deviation. For comparision data in two or more categories we use Mann - Withney U test and Kruskal - Wallis H test. Comapairing the group by certain qualitative sign we use Pearson squere test.

\section{Historical perspective of the development of pediatric palliative care}

The concept of palliative care originally evolved from the hospice philosophy of meeting gaps in care for seriously ill and dying patients. The Latin wordpalliate means "conceal or alleviate symptoms without curing” (Romesburg, 2007). 
In Greece $1000 \mathrm{BC}$ there were special shelters for weary and sick wanderers to die. In the Middle Ages religious orders set up hospices for wanderers. A hospice to care for the dying was opened in 1843 in Lyon.

The forefather of the modern hospice and palliative care movement is Dame Cicely Saunders, who set up the first modern hospice programme in the United Kingdom in 1967 emphasizing the importance of compassionate care and medical science. The St. Christopher's Hospice was opened in the United Kingdom the same year (Georges, Grypdonck, \& Dierckx de Casterle, 2002).

The Dean of Yale University Florence Wald invited Saunders to visit the United States of America for an experience exchange visit in hospice development and in 1974 she started the first home-care programme in Connecticut (Morgan, 2009).

The first pediatric palliative care hospice in England was opened in 1982. (Foster, 2007). In 1990 the World Health Organization introduced and drew up a formal definition of palliative care as "active total care of patients whose disease is not responsive to curative treatment". The World Health Organization describes pediatric palliative care as a total care of the child's body, mind and spirit, also involving support to the family (WHO, 2004). The first pediatric hospices in Eastern Europe were opened in 1994 in Warsaw (Poland) and in Minsk (Byelorussia) (Bjaliks, Buhni, Voloks, \& Ceitlings, 2004).

A palliative care unit for adults was opened in the Oncology Centre of Latvia in 1997 (Sosārs, 2005), whereas the Latvian Society for Children Palliative Care was established in January 1998.

The Society for Children Palliative Care of Latvia provides home-care services since 1998. Initially the pediatric palliative care service operated only in Riga and rendered services only to patients residing in the city of Riga. The participation in various projects and attraction of EU funding made it possible to implement projects for training two mobile palliative care units in the cities of Liepaja and Livani. Due to the shortage of staff currently pediatric palliative care is provided only by the Liepaja team, which renders home-care service. There are several generally accepted palliative care models covering consultative care, outpatient care, inpatient care, home-care and hospice care.

\section{Recipients of pediatric palliative care}

Pediatric palliative care is accessible to children with incurable chronic diseases under the age of 18 years and their family members. Most common disease groups in pediatric palliative care are hemato-oncological diseases, inborn genetic and multiple organ failure, heart, kidney, liver, lung and neurological disorders in late stage, immunodeficiency Feudtner et al., 2002). 
Four different categories of chronic incurable diseases have been identified for pediatric palliative care:

(1) life-threatening conditions where curative treatment may be feasible but may fail and where palliative care may be necessary in addition to treatment;

(2) conditions for which there may be long phases of intensive treatment aimed at prolonging life and allowing participation in normal childhood activities, but premature death is still possible;

(3) progressive conditions without curative treatment options, where treatment is exclusively palliative and may commonly extend over many years; and

(4) conditions with severe, non-progressive neurological disability which may deteriorate unpredictably, causing complications and premature death possibility (Himelstein, 2006).

As there is a wide range of chronic incurable diseases and lack of a specific definition in circumstances where curative medicine subsists alongside with the palliative care, the following relationships between curative and palliative services should be distinguished:

1. With the disease progressing, emphasis is gradually shifted from the curative treatment to palliative care.

2. To prolong and achieve the best possible quality of life, highly invasive treatment may be applied alongside with palliative care, each of these methods at the respective stage of the disease.

3. No treatment is possible and palliative care is applied immediately after diagnosis.

4. Initially it is not clear whether it is an incurable disease, and palliative care is started immediately after approval of this fact (Recommendations of the Committee of Ministers of Member States on the organization of Palliative Care, 2003).

Notwithstanding the group to which the disease of an incurably sick child belongs, there are multiple various profile specialists involved in his/her care. Palliative care patients receive healthcare services in different forms integrated within the pediatric palliative care models.

\section{Pediatric palliative care team}

Palliative care evolves from religion and patient care and not from medical treatment. Due to this the modern palliative care draws heavily on a broad spectrum of disciplines, knowledge, skills and creative thought (Crawford \& Price, 2003). A condition precedent for solving the complex care issues of a patient with limited life expectancy is the involvement of a multidisciplinary team 
in the treatment and care to ensure qualitative assistance (Valadares, Mota, \& Oliveira, 2014).

Palliative care is based upon holistic approach to caring which perceives a human as the totality of all existential dimensions of an individual. The model distinguishes four dimensions: somatic, social, psycho-emotional and spiritual. Any disturbances of one dimension will cause disturbances in others, therefore the palliative care team consists of a multidisciplinary team (Mok, 2004). In case of pediatric palliative care the skills base and personal experience in working with children and their families is of fundamental importance. The individual interpersonal qualities of each specialist play an equally important role for building positive relations with the family and for rendering necessary assistance in crisis situation. Pediatric palliative care is provided by a multidisciplinary care team composed of: palliative care physician, palliative care nurse, social worker specializing in palliative care, chaplain, psychologist and psychotherapist (Ahmedzai et al., 2004).

Children with life-limiting and life-threatening disease and their families have diverse and mutable priorities that include clinical needs, psychosocial needs, social needs and spiritual needs. To provide adequate patient care, however, it is also important to contextualize and assess the needs of the team taking care of these patients and their families, to find new ways to provide patient care (Benini, Spizzichinto, Trapanotto, \& Ferrante, 2008). It is important to involve a multi-disciplinary team in the care of an incurably sick child as soon as possible as early work with the family results in better patient and his/her family oriented care outcomes (Miller et al., 2015). The achievement of these objectives is the most important aim to be achieved by the palliative care team, irrespective of the patient's life expectancy.

\section{Parental satisfaction with palliative care service}

According to the average score provided for the sub-category: mutual cooperation of palliative care organizations $(\mathrm{M}=14.58$, ( $\mathrm{SE}=4.72)$ min.12, max. 36) there is room for the conclusion that patients are not satisfied with the mutual cooperation of the organizations involved in providing palliative care. Considering the fact that the majority of the respondents are parents of children receiving palliative care services, the most impartial indicator to characterise patient satisfaction with the mutual cooperation of the organizations involved in providing palliative care would be satisfaction with the care received at practitioners - specialists at health centres (primary healthcare). The results show overall average satisfaction (46.3\%) with the received service. According to the results, fully satisfied with the received service are parents caring for a child who receives palliative care services for a rather long period of time, whereas 
dissatisfied are parents whose children receive the service for a comparatively shorter period of time.

Presumably, this could be explained with the parental inability to accept the child's disease in short-term perspective as their hope and expectations regarding the child's health condition contradict the explanations provided by medical staff on the disease and its progression what also affects the level of parental satisfaction. These outcomes might also point to the lack of care consistency and proper follow-up care for a patient moving from one care level to another what is one of the most important healthcare quality and patient satisfaction dimensions (Gerteis et al., 1991; Zimmermann et al., 2008). The comparison of the data on patient satisfaction with the pediatric palliative care services depending on the patient's place of residence reveals that the patients living in Riga region are less satisfied with the mutual cooperation of care organizations.

The average score received in the funding sub-category of the patient satisfaction survey $(\mathrm{M}=15.29$, $(\mathrm{SE}=4.50) \min .9$, max. 27$)$ reveals average satisfaction $-39.9 \%$ of the surveyed families in average are satisfied with the frequency of home visits of palliative care specialists under the state-funded palliative care. Fully satisfied with the frequency of home visits are $41.8 \%$ of families living in Riga region, followed by $37.5 \%$ Vidzeme region families. The satisfaction scores could be attributed to the vicinity (in terms of distance) of the patient's residence to the workplace of palliative care specialists, as the majority of the respondents are from Riga region. The result could be equally attributed to the limited number of specialists providing palliative care services, as emotionally it is a very tense work.

The average care consistency and follow-up score provided in the patient satisfaction survey $(\mathrm{M}=6.99$, $(\mathrm{SE}=2.07)$, min. 3, max. 9) reveals that patients are satisfied with the available follow- up care, i.e. $94 \%$ of the surveyed families are satisfied with the possibility to receive palliative care service 24 hours a day 7 days a week. This indicator is equally high for families caring for one and for two children. An incurably sick child is an emotional journey and at times the parents are under permanent strain, and any changes in the child's health condition only increase it. The possibility to address a specialist 24/7 is the starting point for solving problems related to child's health and care. The outcomes are based upon multiform needs and the course of the disease which frequently requires immediate action by medical and care staff. Less satisfied with the availability of follow-up care are families with incurably sick children from Zemgale region. 
Proceedings of the International Scientific Conference. Volume IV, May $25^{\text {th }}-26^{\text {th }}$, 2018. 65-74

Table 1 Satisfaction with the possibilityof receiving palliative care 24/7 depending on number of children in the family receiving palliative care services

\begin{tabular}{|c|c|c|c|c|c|}
\hline \multicolumn{3}{|c|}{ Satisfaction with the continuity of care } & \multicolumn{2}{|c|}{$\begin{array}{c}\text { Number of children in } \\
\text { family }\end{array}$} & \multirow[t]{2}{*}{ Total } \\
\hline & & & 1 child & 2 children & \\
\hline \multirow{4}{*}{$\begin{array}{l}\text { Satisfaction with } \\
\text { the possibilityof } \\
\text { receiving } \\
\text { palliative care } \\
24 / 7\end{array}$} & \multirow{2}{*}{$\begin{array}{l}\text { Partly } \\
\text { satisfied }\end{array}$} & Number (n) & 5 & 3 & 8 \\
\hline & & Percent & $4,0 \%$ & $42,9 \%$ & $6,0 \%$ \\
\hline & \multirow{2}{*}{$\begin{array}{l}\text { Fully } \\
\text { satisfied }\end{array}$} & Number & 121 & 4 & 125 \\
\hline & & Percent & $96,0 \%$ & $57,1 \%$ & $94,0 \%$ \\
\hline
\end{tabular}

The average palliative care availability ratio $(\mathrm{M}=6.12$, $(\mathrm{SE}=3.07)$, min. 4 , max.12) received under the patient satisfaction survey demonstrates low satisfaction in this category. The analysis of the average indicators provided in six sub-categories of the satisfaction survey reveal average satisfaction with the received medical treatment and care services under palliative care. According to a study by Akemi et al. (2012) about $20 \%$ reported that improvement is necessary in physical care by physicians, physical care by nurses and coordination/ consistency of care.

The results of the palliative care accessibility category which characterizes patients' satisfaction with the received healthcare services at patient's home (home care) depending on the age of the child, demonstrate that $64.5 \%$ of the surveyed families were satisfied with the received service. Most dissatisfied with the service were families with a child receiving palliative care living in Zemgale region. Global studies have shown that for promoting accessibility of palliative care in case of limited resources, telephone consultations or telemedicine may be used (Bradford et al., 2014).

The average score of the capacity building category $(\mathrm{M}=15.16$, $(\mathrm{SE}=3.74)$, min.7, max.21) reveals average and high satisfaction with the professional knowledge and skills of care specialists, the educational work and the possibilities to participate in training organized by professionals $-42.4 \%$ of the surveyed families have given an average score for the provided training options. The families from Latgale region are completely satisfied with the availability of training, the patients from Riga region are partially (53.4\%) satisfied, whereas $53.3 \%$ of patients from Vidzeme region are dissatisfied with the offered training options. 
Kalnina \& Deklava, 2018. Parent Satisfaction with Treatment and Care Services Withtin the Framework of Pediatric Palliative Care in Latvia

Table 2 Satisfaction with opportunity to participate in professionas child-care training depending on the place of residence

\begin{tabular}{|c|c|c|c|c|c|c|c|}
\hline \multirow{2}{*}{\multicolumn{3}{|c|}{ Capacity building }} & \multirow{2}{*}{\multicolumn{4}{|c|}{ Place of residence }} & \multirow{3}{*}{$\begin{array}{r}\text { Total } \\
\\
24\end{array}$} \\
\hline & & & & & & & \\
\hline \multirow{6}{*}{$\begin{array}{l}\text { Satisfaction } \\
\text { with } \\
\text { opportunity } \\
\text { to participate } \\
\text { in } \\
\text { professionas } \\
\text { child-care } \\
\text { training }\end{array}$} & \multirow{2}{*}{$\begin{array}{l}\text { Never } \\
\text { satisfied }\end{array}$} & Number (n) & $\begin{array}{r}\begin{array}{c}\text { Riga } \\
\text { reg. }\end{array} \\
14\end{array}$ & $\begin{array}{c}\begin{array}{c}\text { Zemgale } \\
\text { reg. }\end{array} \\
2\end{array}$ & $\begin{array}{l}\begin{array}{c}\text { Vidzeme } \\
\text { reg. }\end{array} \\
8\end{array}$ & $\begin{array}{r}\text { Latgale } \\
\text { reg. } \\
0\end{array}$ & \\
\hline & & Percent & $24,1 \%$ & $25,0 \%$ & $53,3 \%$ & $0,0 \%$ & $28,9 \%$ \\
\hline & \multirow{2}{*}{$\begin{array}{l}\text { Partly } \\
\text { satisfied }\end{array}$} & Number ( & 31 & 2 & 2 & 0 & 35 \\
\hline & & Percent & $\begin{array}{r}53,4 \\
\%\end{array}$ & $25,0 \%$ & $13,3 \%$ & $0,0 \%$ & $42,2 \%$ \\
\hline & \multirow{2}{*}{$\begin{array}{l}\text { Fully } \\
\text { satisfied }\end{array}$} & Number ( & 13 & 4 & 5 & 2 & 24 \\
\hline & & Percent & $22,4 \%$ & $50,0 \%$ & $33,3 \%$ & $100,0 \%$ & $28,9 \%$ \\
\hline
\end{tabular}

The average score received in the sub-category - awareness raising $(\mathrm{M}=3.51$, $(\mathrm{SE}=1.12)$, min.2, max.6) indicates towards average level of satisfaction $-50.9 \%$ of the patients are generally satisfied with the possibility to participate in awareness raising events on children requiring special care. The result could be explained with the increasing popularity of such events. The data obtained under the study on patient satisfaction with awareness raising activities regarding children with special needs are of general nature as the awareness raising and integration of children with special needs into the society is a separate area to be surveyed independently.

\section{Conclusions}

Pediatric palliative care in Latvia is ensured in the form of home hospice care. Home hospice palliative care is provided by a separate team which is part of a health care organization. This model contributes to the possibility for the patient and its family to stay longer at home. The care and support for the patient and its family is provided by a multidisciplinary team.

A fundamental aspect of palliative care is the continuity of care which involves availability and follow-up by healthcare specialists, access to information and other medical treatment and care related resources. On the basis of the average results of the patient satisfaction survey provided in six subcategories, it can be concluded that in average patients are satisfied with the medical treatment and care services received in the form of hospice care. 


\section{References}

Ahmedzai, S. H., Costa, A., Blengini, C., Bosch, A., Sanz - Ortis, J., Ventafridda, V., \& Verhagen, S. C. (2004). A new international frmework for palliative care. European journal of cancer, 40, $2192-2200$.

Akemi, Y., Tatsuya, M., Mitsunori, M., Ayumi, I., Miki, A., Nobuya, A., Yutaka, S., \& Kenji, E. (2012). Pain intensity, quality of life, quality of palliative care, and satisfaction in outpatients with metastatic or recurrent cancer: a Japanese, nationwide, region - based, multicentre survey. Journal of pain and symptom management, 43 (3), 503 - 514.

Benini, F., Spizzichinto, M., Trapanotto, M., \& Ferrante, A. (2008). Pediatric palliative care. Italian Journal of pediatrics, 34 (4), $1-9$.

BPAB reports from January 2012 - December 2014.

Bradford, N. K., Armfield, N. R., Young, J., \& Smith, A. C. (2014). Paediatric palliative care by video consultation at home: a cost minimisation analysis. BMC Health service resources, 28. doi: 10.1186/1472-6963-14-328.

Crawford, G. B., \& Price, S. (2003). Team working: palliative care as a model of interdisciplinary practice. Medicine journal of Australia, 179 (6), 32 - 34.

Feudtner, C., Christakis, D. A., Zimmerman, F. J., Muldoon, J. H., Neff, J. M., \& Koepsell, T. D. (2002). Characteristics of Deaths Occurring in Children's Hospitals: Implications for Supportive Care Services. Paediatrics, 109 (5), 887 - 893.

Foster, T. L. (2007). Pediatric palliative care revisited: a vision to add life. Journal of hospice and palliative nursing, 9 (4), $212-219$.

Georges, J. J., Grypdonck, M., \& Dierckx de Casterle, B. (2002). Being a palliative care nurse in an academic hospital: a qualitative study about nurses perceptions of palliative care nursing. Journal of clinical nursing, 11 (6), 785 - 793.

Gerteis, M., Edgman-Levitan, S., \& Daley, J. (1993). Through the Patient's Eyes. Underrstanding and Promoting Patient-Centered Care. San Francisco: Jossey-Bass.

Himelstein, B. P. (2006). Palliative care for infants, children, adolescents and their families. Journal of palliative medicine, 9 (1), $163-181$.

Miller, E. G., Frizzola, M. A., Levy, C., \& Greenspan, J. S. (2015). Recent experience establishing a new pediatric palliative care team. The journal of pediatric, $166(1), 4-5$.

Mok, E. (2004). Nurse - patient relationships in palliative care. Journal of advanced nursing, 48 (5), $475-483$.

Moor, D., \& Sheetz, J. (2014). Pediatric palliative care consultation. Pediatric clininics of North America, 61 (4), 735 - 747.

Morgan, D. (2009). Caring for dying children: assessing the needs of the pediatric palliative care nurse. Pediatric nursing, 35 (2), 86 - 90.

Pelant, D., McKaffrey, T., \& Beckel, J. (2012). Development and implementation of pediatric palliative care program. Journal of Pediatric nursing, 27, 394 - 401.

Recommendation Rec (2003). 24 of the Committee of Ministers of member states on the organization of palliative care. Adopted by the committee of Ministers on 12. November 2003 at the 860th meeting of the Ministers Deputies Council of Europe, 2005; 1 - 77.

Romesburg, T. L. (2007). Building a case of neonatal palliative care. Neonatal network, 26 (2), $111-115$.

Sosārs, V. (2005). Paliatīvā aprūpe - svinot nozares desmit gadu jubileju. Doctus, 8, 46 - 47.

Valadares, M. T., Mota, J. A. C., \& Oliveira, B. N. (2014). Palliative care in pediatric hematological oncology patients: experience of a tertiary hospital. Brazilian Journal of Hematology and Hemotherapy, 36 (6), 403 - 408. 
Kalnina \& Deklava, 2018. Parent Satisfaction with Treatment and Care Services Withtin the Framework of Pediatric Palliative Care in Latvia

World Health Organization (2003).

Zimmermann, C., Riechelmann, R., Krzyzanowska, M., Rodin, G., \& Tannock, I. (2008). Effectiveness of specialized palliative care: a systematic review. Journal of the American Medical Association, 299 (14), 1698 - 1709.

Бялик, М. А., Бухны, А. Ф., Волох, С. А., \& Цейтлин, Г. Я. (2004). О создании системы паллиативной помощи для детей с онкологическими заболеваниями. Bonpocbl гематологии/онкологии и иммунологии в педиатрии, 4 (4), 61-69. 